\title{
Korrespondenzen. Berichtigung.
}

Die im Anschluß an die Bemerkung des Herrn Professor Dr. Czaplewski zu meinem in Nummer 50, 1912 veröffentlichten Aufsatze: „Ueber eine trachomähnliche Bindehautentzündung etc." gebrachte Notiz entspricht in verschiedenen Punkten nicht dem wahren Sachverhalt.

Es ist unrichtig, daß ich den Aufsatz ohne Wissen und Willen des Institutsleiters veröffentlicht habe. Herrn Prof. Dr. Czaplewski waren vielmehr meine Untersuchungen, iiber die ich schon früher inehrfach geschrieben und Vorträge gehalten habe, genau bekannt, wie or auch wußte, daß ich den hier in Frage stehenden Fall publiziereu würde. Es kann daher von einem Mißbrauch meinerseits keine Rede sein.

Ein solcher ist aber auch nicht darin zu erblicken, daß ich neiner1 Aufsatz. mit dem Untertitel "Aus dem Bakteriologischen Institut Cölnı" veröffentlicht habe. $\mathrm{Z} u$ dieser Art der Publikation war ich nach den bei der Anstalt herrschenden Grundsätzen verpflichtet, obwohl ich als älterer Arzt begreiflicherweise von dieser Bezeichnung lieber Abstand genommen hätte.

Ebensowenig ist mit dem Umstande, daß ich in meinem Aufsatzc stets von ,wir" sprach, beabsichtigt, den Anschein zu erwecken, als wenn Herr Prof. Dr. Craplewski sich mit dem Inhalte meiner Arbeit identifiziere. Die Anwendung dieser Ausdrucksweise stellt lediglich den in wissenschaftlichen Arbeiten allgemein üblichen pluralis majestatis dar.

Meine Handlungsweise kann daher nicht als Mißbrauch angesehen werden, wenn es auch zur Vermeidung der Mißverständnisse zweckmäßig gewesen wäre, auch von dem Wortlaute meiner Arbeit dem Institutsleiter vor der Veröffentlichung Kenntnis zu geben.

Dr. Stiel,

Augenarzt.

Zur Würdigung der obigen „Berichtigung“, deren Abdruck durch einen Kölner Rechtsanwalt unter Androhung einer Klage erzwungen ist, verweise ich auf die in Nr. 2, S. 78 veröffentlichte Erklärung des Herrn Prof. Czaplewski. In einem mir später übersandten Schreiben von Prof. Czaplewski heißt es ferner:

,Herr Dr. Stiel betont, daß er sich inir gegenüber verpflichtet habe, über seine aus unserem Laboratorium herauskommenden Arbeiten zu setzen: ,Aus dem Bakteriologischen Laboratorium etc.'. Er habe aber nicht geglaubt, weiter verpflichtet zu sein, mir die Arbeit vorher vorzulegen, da er das sonst getan hätte. Das ist aber doch - worin Sie mit mir übereinstimmen -- die in allen Laboratorien übliche grundsätzliche Forderung des Placet seitens des Institutsvorstandes. Hier liegt also die Differenz in den Auffassungen von Ihnen und mir einerseits und Dr. Stiel anderseits.

Er meinte, ich hätte den Inhalt der Arbeit gekannt. Dies ist aber doch nur insoweit der Fall, als er mir Präparate vorgelegt und über seine Ideen gesprochen hat, wobei ich ihm übrigens meine gegenteilige Meinung nie verhehlt habe.

Als er bei uns zu arbeiten anfing, hat er von mir erfahren, daß ich selbst schon 1897 (Diese Wochenschrift 1897, Bericht über,die Sitzung der Vereinigung für wissenschaftliche Heilkunde zu Hamburg am 12. April 1897) und später 1909 über Trachom gearbeitet habe. Ich habe ihm auch meine Mikrophotogramme gezeigt. Trotzdem habe ich ihm in vorurteilsfreier Weise in unserm Institut Gastfreundschaft gewährt und über Trachom zu arbeiten gestattet. Er habe, wie er mir sagt, angenommen, daß ich meine Trachomstudien aufgegeben hätte. Dies konnte er nun freilich nicht verlangen. Als mir jetzt das Cölner Trachommaterial zugänglich wurde, habe ich dieselben wieder aufgenommen. Er erfuhr davon, als seine Arbeit bereits im Druck war. Inzwischen habe ich dieselben zu einem vorläufigen Abschluß gebracht und die Resultate gestern, den 21. Januar, durch einen längeren Vortrag im Allgemeinen Aerztlichen Verein zu Cöln mit Lichtbildern publiziert.

Da ich 7.1 ganz anderen Resultaten als Dr. Stiel gekommen war, blieb mir natürlich nichts anderes übrig, als durch die von Ihnen aufgenommenen Bemerkungen die Patenschaft für Dr. Stiels. Arbcit und seine weitgehenden, mil unbekannten, Sichlußfolgerungen (,wir") abzulehnen."

Danach kann jedem einigerınaßen litcrarisch erfahrenen Lescr unserer Wochenschrift das Urteil darüber anheimgestellt bleiben, welcher Wert der .,Berichtigung" des Herrn Dr. Stiel beizumessen ist.

Im übrigen betone ich, daß meine an die Erklärung von Prof. $\mathrm{Czap}$ lcwski angeschlossene Beinerkung durch wiederholte unliebsame redaktionelle Erfahrung hervorgerufen worden ist und nicht dazu dienen sollte, Herrn Stiel zu „,verletzen", sondern weiteren Entgleisungen literarisch unerfahrener Autoren in ihrem eigenen und unserem Interesse vorzubeugen. Ich will dabei gern die Behauptung des Herrn Stiel, daß er sich bei seinem Vorgehen im Recht befunden zu haben glaube, als wahr unterstellen und ihn insoweit von meinem ganz allgemein ausgesprochenen Tadel ausnehmen.

J. Schwalbe. 